\title{
KARIR EFEKTIF DALAM ORGANISASI SELULER
}

\author{
Nur Wening
}

\begin{abstract}
The effectiveness in career management will certainly enhance a greater appropriateness between personnel and functions they are in charge of which ultimately results in developing their competence and placing the right persons in key positions. In traditional approach, promotion should be started from specific functions to higher ranks; in other words, an employee could only develop his career step by step. A recent development in career management to cope with the growth of the organization is the concept of a cellular organization consisting of independent groups or autonomous business units showing their independent existence and interacting one another to from a bigger organism. Career in such organization is known as protean career the aim or which is not just for promotion and improvement in salaries but also in psychological successes. This article tries to discuss how far van protean career be implemented in cellular organizations.
\end{abstract}

Keywords: Cellular organization, traditional career, protean career 


\section{Vol 1. No I}

\section{PENDAHULUAN}

Lingkungan bisnis yang terus berubah, menuntut setiap pelaku bisnis senantiasa melakukan adaptasi dengan pola perubahan tersebut agar tetap kompetitif. Begitu juga organisasi yang mengalami perubahan sejalan dengan perubahan lingkungan bisnis tersebut. Seiring perubahan-perubahan tersebut berbagai tantangan dalam bidang MSDM atau Human Resource Management muncul, sehingga perlu dilakukan antisipasi agar organisasi tetap suvive dan kompetitif khususnya dengan dukungan SDM yang kuat.

Pola karir manajerial adalah salah satu aspek yang diperkirakan akan mengalami banyak perubahan di masa yang akan datang. Karakteristik karir di masa datang yang meliputi kemampuan spesialisasi, pengalaman internasional, keunggulan dalam kerja sama, keahlian mengatur diri sendiri serta sifat fleksibel, integritas dan kepercayaan. Kondisi tersebut akan memiliki sejumlah dampak, diantaranya terhadap perkembangan struktur organisasi sehingga diharapkan muncul suatu bentuk pada wilayah geografis masing-masing. Jalur karir menuntut kompetensi yang bersifat lintas disiplin ilmu. Sehingga karyawan dituntut memiliki kemampuan teknis, kemampuan mengembangkan pribadi dan kemampuan bersaing secara komersial.

Organisasi matriks. Bentuk struktur ini dimulai dasawarsa 60-an, terjadi karena konsumen menuntut untuk dijadikan client atau rekanan. Organisasi dibentuk dengan cara memadukan struktur fungsional dan divisional. Bentuk ini memiliki kekurangan yaitu nampak kaku jika dihadapkan pada perubahan yang semakin cepat. Pada pengembangan karir, organisasi menuntut karyawan mampu memadukan secara lengkap kemampuan teknis, komersial dan selfgovernance skill yang dimilikinya.

Organisasi network. Intensitas persaingan domestik dan internasional meningkat sementara bentuk organisasi yang ada dirasakan kurang mampu mengakomodasi persaingan, karena dinilai terlalu birokratis dan kaku. Sebagai solusinya dilakukan downsizing, delayering dan outsourching. Kegiatan ini dipelopori perusahaan sperti Nike, Motorolla dan Novell dan setelah itu bentuk organisasi networks mulai muncul dimana-mana. Organisasi ini dibentuk dari hubungan perusahaan-perusahaan independen agar menghasilkan keahlian yang diperlukan bagi proyek-proyek khusus. Keunggulannya adalah adanya investasi yang berkelanjutan untuk 


\section{Vol 1. No I}

pelatihan dan pendidikan seluruh anggota organisasi. Selain itu juga perusahaan tidak menginvestasikan dana dalam fasilitas produksi dana dapat menciptakan full partner.

Dalam organisasi network tenaga kerja memiliki kemungkinan untuk berkarir di luar perusahaannya, sesuai keahlian dan ketrampilan yang dimiliki. Sebaliknya perusahaan berpeluang memiliki tenaga kerja yang memiliki pengetahuan serta ketrampilan yang dibutuhkan tanpa memiliki secara tetap karyawan tersebut (outsourching).

Organisasi selular. Organisasi ini dibangun atas sel-sel (yaitu tim-tim yang mengelola dirinya sendiri) yang akan membentuk dirinya sendiri. Jika antar sel melakukan interaksi maka akan menghasilkan organisme yang potensial, kinerja lebih kompleks dan kompeten. Pada bentuk organisasi ini dapat dilihat adanya perubahan kompetensi manajerial yang dibutuhkan. Fungsi organisasi dengan anggota merupakan hubunganprofesional yang bersifat knowledge sharing dan tanggung jawab atas kompetensi kinerja anggota.

Anggota organisasi akan menanggung dan mempunyai kewenangan penuh terhadap jalur karirnya, oleh karena itu pengembangan karir selanjutnya tergantung pada kreativitas serta inisiatif setiap karyawan. Peranan organisasi atau manajemen hanya sekedar memberikan fasilitas agar setiap sel mampu berkembang lebih baik.

Perbedaan setiap bentuk organisasi seperti yang dijelaskan di atas, dapat dilihat pada tabel 1 .

Tabel 1. Comparison Between Traditional-Modern Organizational Careers

\begin{tabular}{|l|l|l|l|}
\hline \multicolumn{1}{|c|}{$\begin{array}{c}\text { Organization } \\
\text { Structure }\end{array}$} & \multicolumn{1}{|c|}{ Career path } & \multicolumn{1}{|c|}{ Key Competence } & $\begin{array}{c}\text { Responsibility for } \\
\text { career planning }\end{array}$ \\
\hline Functional & $\begin{array}{l}\text { Single firm, within } \\
\text { Function }\end{array}$ & $\begin{array}{l}\text { Technical } \\
\text { department }\end{array}$ \\
\hline Divisional & $\begin{array}{l}\text { Single firm, across } \\
\text { division }\end{array}$ & $\begin{array}{l}\text { Technical, } \\
\text { commercial }\end{array}$ & Division Firm \\
\hline
\end{tabular}




\section{Vol 1. No I}

\begin{tabular}{|l|l|l|l|}
\hline Matrix & $\begin{array}{l}\text { Single firm, Across } \\
\text { project }\end{array}$ & $\begin{array}{l}\text { Technical, } \\
\text { commercial }\end{array}$ & $\begin{array}{l}\text { Department Project } \\
\text { Firm }\end{array}$ \\
\hline Network & $\begin{array}{l}\text { Within and across } \\
\text { firms }\end{array}$ & $\begin{array}{l}\text { Technical, } \\
\text { commercial and } \\
\text { collaborative }\end{array}$ & Firm and Individual \\
\hline Cellular & Independent, & $\begin{array}{l}\text { Technical, } \\
\text { commercial, } \\
\text { collaborative and self } \\
\text { governance }\end{array}$ & $\begin{array}{l}\text { Individual } \\
\text { colaborative and self } \\
\text { governance }\end{array}$ \\
\hline
\end{tabular}

Sumber: Alfred, B. B., et al., 1996, Characteristic of managerial careers in $21^{\text {st }}$ century “, Academy of Management Executive.

\section{PEMBAHASAN}

Kemampuan dan kecakapan karyawan, dukungan serta bentuk organisasi akan sangat menentukan jenjang karir seseorang. Perencanaan karir yang dilakukan dalam organisasi tradisional jelas berbeda dengan organisasi modern (Alfred, B.B.,et al., 1996). Karir seseorang ditentukan oleh organisasi yang mempekerjakan orang tersebt, ini menurut pandangan organisasi tradisional. Jenjang karir seseorang hanya mengacu pada struktur hierarki yang ada, sedangkan organisasi sellular akan mampu memberikan manfaat bagi kelompok profesional dan asosiasi proffesional untuk mengambil bagian dalam karir mereka, dengan meningkatkan kegiatan pembelajaran bagi anggotanya. Organisasi selular dibentuk berdasarkan self managing team dan autonous business units. Sedangkan pada jenjang karir tradisional karyawan dapat mencapai kemajuan vertikal, yaitu melalui kenaikan dari jabatan spesifik (tertentu) ke jabatan berikutnya. Dengan kata lain karyawan harus bergerak selangkah demi selangkah.

Perkembangan karir yang mengikuti bentuk organisasi sebagaimana dijelaskan diatas adalah konsep organisasi yang terdiri atas kelompok mandiri atau unit bisnis otonom yang akan menunjukkan keberadaannya secara mandiri, dan melakukan interaksi satu sama lain untuk membentuk organisme yang lebih besar (Alfred, et al, 1996). Efektivitas dalam manajemen karir 


\section{Vol 1. No I}

akan mengurangi ketidaksesuaian antara orang dan peran yang dimainkan, kemudian akan mampu membangun kompetensi serta menempatkan orang pada posisi kunci. Sesuai dengan makna karir seperti yang disebutkan diatas maka model karir yang dipandang cocok adalah protean career, seperti yang nampak dalam tabel 2. Karir dalam bentuk organisasi seperti ini dikenal sebagai protean career (Hall, 1996).

Tabel 2. Perbandingan Antara Karir Tradisional Dan Karir Protean Di Abad 21

\begin{tabular}{|l|l|l|}
\hline \multicolumn{1}{|c|}{ Dimension } & \multicolumn{1}{|c|}{ The Protean Career } & \multicolumn{1}{c|}{ Traditional Career } \\
\hline Tujuan & Sukses Psikologis & Promosi, kenaikan gaji \\
\hline Kontrak Psikologis & $\begin{array}{l}\text { Kemampuan dipekerjakan } \\
\text { (untuk Fleksibilitas) }\end{array}$ & $\begin{array}{l}\text { Jaminan kemanan karir } \\
\text { (untuk meningkatkan } \\
\text { komitmen karyawan })\end{array}$ \\
\hline Penanggung jawab karir & Individu & Organisasi \\
\hline Pola & Spiral dan transitory & $\begin{array}{l}\text { Linier dan menuntut } \\
\text { spesialisasi }\end{array}$ \\
\hline Keahlian & Learn-how & Know-how \\
\hline Pengembangan & Pengalaman Kerja & Pelatihan formal \\
\hline
\end{tabular}

Sumber: Hall, D.T., (1996), Protean Career in the $21^{\text {st }}$ century, Academy of management;

Nicholson, (1996), Career Systems in crisis; Change and opportunity in the information age, Academy of Management.

Menurut Hall (1996) dalam karir protean kontrak karir pada awal milenium tidak lagi terikat kontrak kerja tradisional, misalnya dalam melakukan kerja, memiliki kinerja baik, memiliki komitmen, menerima kompensasi dan sebagainya. Kontrak yang baru akan lebih didasarkan pada continous learning serta perubahan identitas yang disebut sebagai the path with a heart (Hall, 1996). Kontrak karir awal milenium (abad 21) akan memiliki karakteristik: protean career, psychological succes, contious learning, sources of development dan profil 


\section{Vol 1. No I}

kesuksesan (tuntutan pasar kerjalearn how, employability, kesadaran dan tanggung jawab individu, win win yang lebih fair). Karir protean ditentukan oleh dirinya sendiri (individu karyawan) tidak ditentukan oleh organisasi, sehingga dapat dinyatakan bahwa karir organisasi bisa mati tetapi karir protean tetap hidup dan bersemi sepanjang masa bahkan semakin cemerlang (Widawati, 2001). Menurut Noe, et al. (2000) karir protean adalah karir yang sering meng alami perubahan seiring dua perubahan yang terjadi, yaitu perubahan kepentingan, kemampuan dan nilai seseorang serta perubahan lingkungan kerja itu sendiri.

Tujuan karir protean adalah kesuksesan psikologis, ditandai dengan perasaan bangga atas tercapainya cita-cita, kebahagiaan keluarga, serta kedamaian diri. Melalui pembelajaran (learning) yang berkelanjutan serta perubahan identitas akan dapat dicapai karir yang dimaksudkan. Tantangan kerja dan hubungan dengan pihak lain dalam menjalin kerjasama untuk menunjang karir individu hendaknya diberikan oleh organisasi. Terdapat dua dimensi belajar, yaitu apa yang harus dicapai dalam jangka pendek dan jangka panjang. Dalam jangka pendek seseorang harus mampu meningkatkan kinerja dan selalu memperbaiki perilakunya, sedangkan dalam jangka panjang karyawan selalu meningkatkan kemempuan diri dan pengembangan diri agar dapat melakukan adaptasi terhadap perubahan lingkungan. Yang perlu diingat juga adalah bahwa proses learning tersebut tidak akan terlepas keberadaan pihak lain, sehingga diperlukan adanya hubungan melalui relational learning, mutuality serta saling memberi dan menerima (reciprocity).

Tabel diatas juga menjelaskan bahwa dalam karir tradisional karyawan tidak memiliki banyak peluang guna mengetahui mengapa dia melakukan pekerjaan. Sebaliknya yang terjadi pada model karir baru, karyawan diberi kesempatan serta dituntut belajar, mengetahui mengapa tugas harus dilakukan dan kepada siapa harus bertanggung jawab. Dalam karir protean diharapkan karyawan ikut lebih bertanggung jawab juga atas keberhasilan organisasi. Dijelaskan juga bahwa pencapaian kesuksesan tidak hanya cukup dengan "mengetahui sesuatu" saja tetapi menjadi "bagaimana mempelajari sesuatu” dengan mengevaluasi kekurangan yang dimiliki.

Sukses protean karir dalam organisasi selular atau virtual tidak hanya terletak pada keahlian teknis dan kerja sama, akan tetapi tergantung juga pada peran pemimpin serta self 


\section{Vol 1. No I}

governance skill. Sebab dasar dalam organisasi ini adalah kepercayaan (trust) dan keterikatan antar anggota, sehingga setiap individu akan mampu menciptakan peluang baru dalam bisnis.

\section{IMPLIKASI MANAJERIAL}

- Meskipun anggota organisasi bertanggung jawab serta mempunyai kewenangan penuh terhadap jalur karir dan pengembangan kair selanjutnya, namun peran organisasi atau manajemen sangat penting dalam memberikan fasilitas dan sistem yang mendukung agar setiap sel mampu berkembang lebih baik. Dengan kata lain manajemen harus memfasilitasi dan memberikan dukungan anggota organisasinya dalam menentukan jalur karirnya.

- Top eksekutif organisasi dalam hal ini harus mampu mengasah ketajamn dalam mengamati bakat, minat, kemampuan dan aspirasi anggota organisasi. Ini dapat dilakukan dengan berbagai bentuk penilaian danevaluasi, melalui pemebrian tugas misalnya, kepada anggota organisasi. Hal ini terkait dengan adanya tuntutan kontribusi dari anggota. 


\section{Vol 1. No I}

\section{KESIMPULAN}

Perubahan struktur organisasi seiring dengan perubahan lingkungan bisnis, telah mengubah bentuk karir tradisional yang menuntut organisasi serta individu untuk menyesuaikan diri. Kondisi demikian menekankan pada kemampuan individu di dalam pengembangan karirnya. Manajemen karir yang efektif akan mampu mengurangi ketidaksesuaian antara karyawan dengan peranannya, mengembangkan kompetensi dan menumbuhkan ketersediaan tenaga kerja yang mampu menciptakan kombinasi bakat yang harmonis dan optimal, pengembangan bakat yang fleksibel dan pembelajaran dinamis. Kesuksesan karir protean tidak hanya terletrak pada keahlian teknis dan kerjasama, tetapi tergantung juga pada peran pemimpin serta self governance skill. Sebab dasar dalam organisasi ini adalah kepercayaan (trust) dan keterikatan antar anggota. 


\section{Vol 1. No I}

\section{Daftar Pustaka}

Alfred B. Brent, Snow C Charles and Miles E raymond, 1996, Characteristics Of Managerial Careers Inthe $21^{\text {st }}$ century, Academy Of Management Executive, Vol. 10 (4): 17-27.

Anakwe, U. P., James C. Hal and Susan M. Schor, 2000, Knowledge related skills and effective career management, International Journal Of Manpower, Vol. 21(7):566-579.

Cahyono, B., 2000, Antisipasi karir manajerial abad-21 dalam celluler organization, Usahawan, No.05 Th XXIX, Mei: 16-20.

Fatmawati, I., 1999, Karir Manajerial Abad 21, Usahawan, No.07 Th XXVIII, Juli: 28-34.

Gaertner, Karen N., 1988, Manager's Careers And Organizational Change, Academy Of Management, November: 311-318.

Gibson, J.L., Ivancevich, J.N., Donelly Jr, James, H., 1996, Organizational Behavior,Structure, Process, $8^{\text {th }}$ Ed., Ricard D Irwin Inc.

Greenberg, J. And Robert A. Baron, 1995, Behavior In Organization Understanding And Managing The Human Side Of Work, $5^{\text {th }}$ Edition, Prentice Hall International Edition.

Greenhaus, J.H., Gerard A Callanan and Veronica M Godshalk, 2000, Career Management, $3^{\text {rd }}$ Edition, New York: Dryden Press.

Hall, D., T., 1996, Protean Careers Of The $21^{\text {st }}$ Century”, Academy Of Management Executive, 10: 8-16.

Ida Ayu P. W., 2001, karir Abad 21, Usahawan, No. 02 Th XXX, Februari: 22-26.

Nicholson, N., 1996, Career system in crisis: change and apportunity in the information age, Academy Of Management Executive, 10.

Noe, et al., 2000, Human Resource Management: Gaining A Competitive Advantage, $3^{\text {rd }}$, International Edition, USA: McGraw Hill Co. Inc.

Puryandari, S., 2001, Perencanaan karir yang efektif: tinjauan dari sisi karyawan dan organisasi, Telaah Bisnis, Vol. 2 (1), Juli:17-25.

Rivai, H., A., 2000, Career Resilience: Paradigma baru dalam pengembangan karir, Usahawan, No.01 Th XXIX, Januari: 22-28.

Widowati, M., 1999, Karir lentur model pengelolaan karir masa depan, Usahawan, No.02 Th XXVII, Februari:33-37. 
Journal Competency of Business

2017 Vol 1. No I 